encountered or in a series of useful and extensive appendices. The intelligent reader can thereby constructively use the text without constant recourse to other mathematical texts.

The author, having briefly described the experimental evidence which led to the introduction of quantum mechanics, immediately sets out the postulates of quantum theory and develops the Schrödinger and Heisenberg "pictures" which are both made use of in the following chapters. A number of traditional quantum mechanical problems which are amenable to exact solution are then treated while the later chapters deal with approximation methods, molecular structure and spectroscopy.

Anderson's style is very lucid and it is clear that he has, at all times, been conscious of the difficulties which are encountered by many students when they first meet this subject. While he makes no attempt to avoid the appropriate mathematical description of a situation, ho develops his argument slowly and logically so as not to lose the reader. Exercises are set as an integral part of the text with more advanced problems (solutions are given) at the end of each chapter. Computer programs in FORTRAN II and FOR'TRAN IV are given for certain. specific problems in a separate section to emphasize the importance of digital computation in quantum mechanics. One of the longer programs was selected at random and checked by me and found to be satisfactory.

The book is well produced and after careful reading only half a dozen or so small typographical errors were noted. No price is stated. It would be a pity if this book were to be placed beyond the means of its potential readership.

E. L. SHORT

\section{HAEMS AND CHLOROPHYLLS}

Heme and Chlorophyll

Chemical, Biochemical and Medical Aspects. By Gerald S. Marks. Pp. xiii +208 . (Van Nostrand: London and Princeton, March 1969.) $75 s$.

A KNOWLEDGE of the chemistry and biochemistry of the various haems and haem proteins and chlorophylls is important to workers in an unusually wide variety of disciplines. Because the cytochromes were first discovered by McMunn nearly a century ago and haemoglobin was recognized as a protcin with the iron complex of proto. porphyrin 9 as prosthetic group, numerous haem proteins have been isolated, purified and the structure of their prosthetic groups determined. These include myoglobin, numerous cytochromes, catalases, peroxidases and other enzymes such as tryptophan pyrrolase.

The pioneer work of Hans Fischer on the structure of porphyrins and their iron complexes, the haems, and subsequent work leading to our knowledge of structure and properties of haern proteins and of the biosynthetic pathway to haem, chlorophylls and to the cobalt-containing vitamin $B_{12}$ can be fully appreciated only by specialists working in the ficld. These topics have been the subject of a number of reviews and special volumes, including Fischer's Die Chemie des Pyrroles, Lemberg and Legge's Haematin Compounds, and the report by Falk, Lemberg and Morton of the Canberra Symposium on Haematin Enzymes. These are mainly for the specialist and since their publication there have been many recent develop. ments concerning the control of the biosynthetic mechanisms concerned.

This volume provides a first class general account of these compounds; clearly and concisely written, it deserves to be read by all scientific or medical workers whose interests impinge on this field.

A chapter on haem proteins and tetrapyrrolic compounds generally is followed by that on the degradative and synthetic aspects of the chemistry of haem and chlorophyll, which is the best and most concisc account I have encountered. For the laboratory worker there is a useful chapter on techniques for working with tetrapyrroles and their precursors. Although other reviews have considered the physical absorption and infrared spectra of tetrapyrroles, this is the first which includes a general account of their proton resonance and mass spectra. A chapter on the biosynthosis of haem and chlorophyll is followed by an up to date discussion of the clinical and experimental forms of porphyria.

It is difficult to fault this book, bearing in mind the readers for whom it is intended. Perhaps one would like to have seen a more up to date account of the breakdown of haem proteins to bile pigments and of the algac bile pigments, topics which, however, were discussed fully at a symposium ${ }^{1}$ of the Biochemical Society in May 1968. One regrets, too, that the author has presented the bis-hydroxyl structures of bile pigments for bilirubin and biliverdin but correctly gives the keto-imide structures for the algal pigment phycoerythrobilin. This little volume will stimulate organic chemists to consider problems of the brological and clinical importance of the haem proteins and the related magnesium-containing chlorophylls and the cobalt-containing corrins, and it will stimulate the clinician to examine their chemistry in greater detail.

$$
\text { C. H. Gray }
$$
1 Porphyrins and Related Compounds (edited by 'T. W. Goodwin) (Academic
Press: London and New York, 1968.)

\section{BASIC BIOLOGY}

Molecular Biology

A Structural Approach. By C. U. M. Smith. Pp. $404+10$ plates. (Faber: London, December 1968.) 85s.

A TARGE number of books has been published in the past few years which attempt to expound, for the benefit of non-specialist readers, the various areas of scientific research which are contained within the subject of molecular biology. As a visit to any good bookshop will confirm, there are now in print many well written and skilfully illustrated books available at moderate cost which offer stimulating accounts of the recent advances on the structure and function of biological macromolecules, cell biology and genetics. Individual topics of molecular biology are also the subject of many excellent magazine articles written at a popular level. The book under review represents yet another addition to this very active branch of scientific writing, and it, too, is intended for the general reader, so that comparison with its many competitors is inevitable.

This volume is noteworthy for the extent to which it attempts to provide some slight idea of the basic ideas, particularly those relating to chernical bonding and structure, from which any real apprceiation of molecular biology must be derived. Thus the first three chapters on "the primary substance", atoms and molecules provide, somewhat breathlessly, a sketch of such concepts as bond lengths, electronegativity, bond energies and wrak interaction forees. These ideas are freely used in the subsequent discussion of the primary, secondary and tertiary structure of proteins. This section contains excellent accounts of the structural proteins and the structures of myoglobin and haemoglobin, including also a brief account of the function of haemoglobins, the abnormal hacmoglobins and "molecular discases". The subject of protein structure is completed by a brief but clear discussion of enzyme structure and function and of the way in which some proteins are formed from subunits. There is a very good section on lipid assemblies and biomembranes, and simple accounts of energy transducers and the internal organization of cells.

The last three chapters deal with DNA, the genetic 